\title{
Investigation on the self-association of an inorganic coordination compound with biological activity (Casiopeína III-ia) in aqueous solution
}

Alejandro Marín-Medina', Juan Carlos García-Ramos ${ }^{2,3}$, Lena Ruíz-Azuara² and Ernesto Carrillo-Nava ${ }^{\text {* }}$

\begin{abstract}
From studies using different experimental techniques employed to determine the presence of aggregates e.g. isothermal titration calorimetry, surface tension, electrical conductivity, UV-Vis spectrophotometry, dynamic and static light scattering, it is clearly demonstrated that the compound [Cu(4, 4'-dimethyl-2, 2'-bipyridine)(acetylacetonato) $\mathrm{H}_{2} \mathrm{O} \mathrm{NO}_{3}$ (Casiopeína III-ia), promising member of a family of new generation compounds for cancer treatment, is able to auto associate in aqueous media. Physicochemical properties associated with the formation of the aggregates were determined in pure water and in phosphate buffer media in order to simulate physiological conditions. From isothermal titration calorimetry and electrical conductivity measurements we calculated the dissociation constant of the aggregates, $K_{D}$. For pure water the values obtained in both techniques are $2.73 \times 10^{-4}$ and $5.93 \times 10^{-4} \mathrm{M}$ respectively while for the buffer media we obtained $4.61 \times 10^{-4}$ and $1.57 \times 10^{-3} \mathrm{M}$. The enthalpy of dissociation, $\Delta H_{D}$ calculated from the calorimetric data shows that the presence of the phosphate ions has an energetic effect on the aggregate stability since in pure water a value of $18.79 \mathrm{~kJ} \mathrm{~mol}^{-1}$ was obtained in comparison with the buffer media where a value 4 times bigger was found $\left(70.48 \mathrm{~kJ} \mathrm{~mol}^{-1}\right)$. With the data collected from these techniques the number of monomers calculated which participate in the formation of the aggregates is around two. From our surface tension, electrical conductivity and UV-Vis spectrophotometry measurements the critical aggregate concentration, cac, was determined. For each technique specific concentration ranges were obtained but we can summarize that the cac in pure water is between 3 and $3.5 \mathrm{mM}$ and for the buffer media is between 3.5 and $4 \mathrm{mM}$. Dynamic light scattering measurements provide us with the hydrodynamic diameter of the aggregates and from static light scattering measurements we determined the molecular weight of the Casiopeína IIl-ia aggregates to be of $1000.015 \mathrm{~g} \mathrm{~mol}^{-1}$ which is two times the molecular weight of the Casiopeína III-ia molecule. This value is in agreement with the number of monomers which participate in the formation of the aggregates obtained from isothermal titration calorimetry and electrical conductivity data analysis.
\end{abstract}

Keywords: Casiopeína, Critical aggregate concentration, Isothermal titration calorimetry, Surface tension, Dynamic light scattering

\footnotetext{
*Correspondence: ernesto.carrillo@unam.mx

${ }^{1}$ Laboratorio de Biofisicoquímica, Departamento de Fisicoquímica,

Facultad de Química, Universidad Nacional Autónoma de México, Mexico,

D. F. 04510 , Mexico

Full list of author information is available at the end of the article
} 


\section{Background}

The coordination complex $[\mathrm{Cu}(4,4$ '-dimethyl-2, 2'-bipyridine)(acetylacetonato) $\left.\mathrm{H}_{2} \mathrm{O}\right] \mathrm{NO}_{3}, \quad$ Casiopeína III-ia, (Fig. 1) is a member of a group of compounds patented and registered under the generic name of Casiopeínas [1, 2]. They are metal complexes which have been developed as a new generation of copper coordination complexes to be used as pharmaceuticals, diagnostic agents or as chemotherapeutic drugs. Some members of the family of Casiopeínas have shown cytotoxic, genotoxic and antineoplastic activity both in in vitro and in vivo studies [3-5]. Casiopeína III-ia is one of the most promising members of this family of compounds and it is currently under phase I clinical trials. Although the mechanism of action is not known with great detail at the molecular level, several experimental results seem to indicate that the two main factors for the cytotoxic induction on human tumor cell are: (i) the generation of reactive oxygen species and (ii) direct interaction with DNA. Experimental observations showed that different members of the family of the Casiopeínas present nuclease activity in contact with DNA, comparable to that shown by other metal complexes [6]. These results allowed to design and perform an experiment of the whole genetic expression of tumor cells exposed to Casiopeínas, where it was found that particular pathways related with the cell cycle, gene expression, cellular growth, proliferation and cell death were affected, all of them related with oxidative stress and DNA damage [7].

The aim of studies related with the formation of specific interactions between the Casiopeínas with important biological targets such as DNA or proteins is to further advance in the understanding of the possible mechanism of action of these compounds, which will provide us with information in order to guide an intelligent

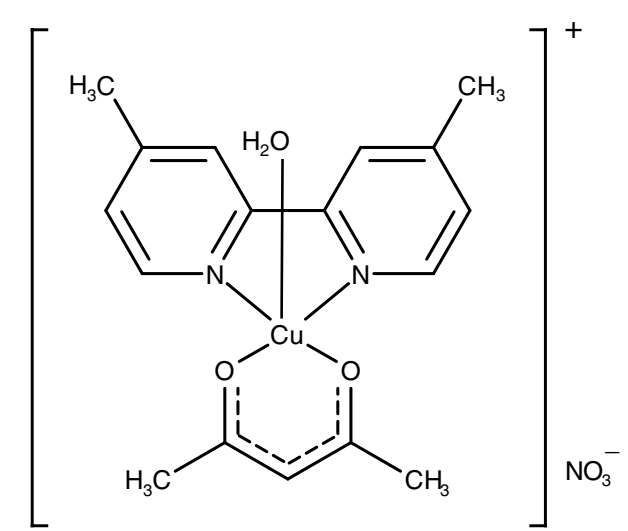

Fig. 1 Chemical structure of $\left[\mathrm{Cu}\left(4,4^{\prime}\right.\right.$ - dimethyl-2, 2'-bipyridine) (acetylacetonato) $\mathrm{H}_{2} \mathrm{O} \mathrm{NO}_{3}$ (Casiopeína III-ia) development of drugs with an increased specificity and reduction of undesirable side effects. During the course of studies involving the formation of protein-Casiopeína III-ia complexes we have found that at the concentrations in which our experiments were being carried out Casiopeína III-ia was self-associating in the buffer media employed to simulate physiological conditions, a feature which had not being identified to our knowledge. Since it is known that the surface and self-association properties of pharmacologically active compounds play an important part in the mechanisms of the biological activity of such compounds [8], it is of utmost importance to study and characterize the different physicochemical properties of the Casiopeína III-ia aggregates. It is therefore of interest to determine the critical aggregation concentration, cac, the equilibrium constant of dissociation, $K_{D}$, the enthalpy of dissociation, $\Delta H_{D}$, and the aggregation number of the Casiopeína III-ia aggregates using different experimental techniques.

The findings we report in this work are relevant for studies involving the formation of protein-Casiopeína III-ia complexes. It is known that protein-substrate interactions are governed by the specificity and selectivity of the binding site of the protein to the substrate [9]. Experimental conditions must then be precisely established in order to carry out studies where the precise state of aggregation of the substrate is known so the physicochemical properties which characterize the protein-Casiopeína III-ia complex (formation constant, formation enthalpy, stoichiometry, etc.) are unambiguously defined for the species involved in the formation of the complex. These studies are in need in order to elucidate the Casiopeína III-ia mechanism of action or to use proteins as Casiopeína III-ia carriers.

\section{Experimental section \\ Materials and solutions}

Casiopeína III-ia was synthesized following the procedure reported in the literature and was obtained with a purity higher than $99 \%[1,2]$. Milli-Q water with a resistivity of $18.1 \mathrm{M} \Omega \mathrm{cm}^{-1}$ was used to prepare all solutions, the salts used to prepare the two buffer solutions studied in this work were $\mathrm{Na}_{2} \mathrm{HPO}_{4} \cdot 7 \mathrm{H}_{2} \mathrm{O}, \mathrm{NaH}_{2} \mathrm{PO}_{4} \cdot \mathrm{H}_{2} \mathrm{O}$ and $\mathrm{KNO}_{3}$, all analytical grade and purchased from Baker. The range of the concentrations studied was limited from 0.5 up to $10 \mathrm{mM}$ due to the poor solubility that Casiopeína III-ia presents in water and in the two buffer media reported in this work.

From previous studies we have found that the phosphate ion can replace one or both of the organic ligands which make up Casiopeína III-ia. Following the change in the absorbance spectrum by UV-Visible spectrophotometry we have determined that the replacement process 
is not instantaneous but it takes around three weeks. In order to ensure that the physicochemical properties of Casiopeína III-ia are properly determined in all our measurements, freshly prepared solutions of Casiopeína III-ia were employed during the course of our studies.

\section{Isothermal Titration Calorimetry (ITC)}

Heats of dissociation of the Casiopeína III-ia aggregates in pure water and in phosphate buffer $0.1 \mathrm{M}, \mathrm{pH} 7.4$ were measured at $25^{\circ} \mathrm{C}$ using a VP ITC instrument (Microcal, Northampton USA). The syringe of the calorimeter was filled with $10 \mathrm{mM}$ Casiopeína III-ia solutions of either one of the two aqueous media mentioned above and titrated into the cell which only contains the matching media in order to avoid additional heat development due to aqueous media mismatch and the corresponding heat of dilution. The Casiopeína III-ia and the different aqueous media solutions were degassed before being loaded into the syringe and the reaction cell of the calorimeter. Titrations of $5 \mu \mathrm{L}$ spaced by $700 \mathrm{~s}$ were carried out. The calorimetric signals were integrated to obtain the corresponding heats associated with each addition of the Casiopeína solution into the matching aqueous media with the Origin 7.0 (OriginLab Corporation, Northampton, U. S. A.) software macros supplied by the manufacturer.

\section{Surface tension measurements}

The concentration dependence of the surface tension of the aqueous solution and the phosphate $0.1 \mathrm{M}$, $\mathrm{KNO}_{3} 0.1 \mathrm{M}$ and $\mathrm{pH}$ 7.4 solution of Casiopeína III-ia were determined by means of a K12 Krüss tensiometer (Hamburg, Germany) which employs the Du Noüy ring method. All the measurements were carried out at a constant temperature of $25 \pm 0.1{ }^{\circ} \mathrm{C}$ and collected from three independent solution preparations.

\section{Conductivity measurements}

The electrical conductivity of the aqueous solutions and the phosphate $0.1 \mathrm{M}, \mathrm{KNO}_{3} 0.1 \mathrm{M}$ and $\mathrm{pH} 7.4$ solutions of Casiopeína III-ia was determined using an Oakton CON 110 conductometer (Oakton Instruments, Vernon Hills, U. S. A.) at $25 \pm 0.1{ }^{\circ} \mathrm{C}$ which has an accuracy of $\pm 1 \%$ in the full scale and the alternating current supplied to the bridge has a frequency of $2 \mathrm{kHz}$. During the determination of the conductivity of the different Casiopeína III-ia solutions the samples were stirred and between measurements of the different solutions the conductivity cell was cleaned thoroughly with Milli-Q water and rinsed with a small amount of the sample of the new solution from which conductivity data was to be measured.

From plots of the observed molar conductivity, $\Lambda_{\mathrm{obs}}$, as a function of the square root of the concentration and establishing an equilibrium constant for the formation of aggregates from monomer species, it is possible to fit the experimental data to the equations relating the molar conductivities of each of the species involved in the equilibria as well as the equilibrium constant, and the aggregation number. We have performed the data analysis of the observed molar conductivity following the procedure described in detail by Streng et al. [10].

\section{UV-Visible spectrophotometry}

The absorbance of the colored Casiopeína III-ia solutions was measured using a Cary 50 Bio spectrophotometer (Varian, Australia) at $25 \pm 0.1{ }^{\circ} \mathrm{C}$. The concentration dependence of the absorbance for the solutions in the different media was collected from three different solution preparations. Between measurements of the different solutions the optical cell was cleaned thoroughly with Milli-Q water and rinsed with a small amount of the sample of the new solution from which absorbance data was to be collected.

\section{Dynamic light scattering (DLS) and Static light scattering (SLS) analysis}

DLS measurements were performed employing a Zetasizer $\mu \mathrm{V}$ (Malvern, Worcestershire, United Kingdom) light scattering instrument which is equipped with a 60 $\mathrm{mW} \mathrm{He}-\mathrm{Ne}$ laser, operating at a wavelength of $830 \mathrm{~nm}$. Light intensity was collected at an angle of $90^{\circ}$ and at a fixed temperature of $25 \pm 0.1{ }^{\circ} \mathrm{C}$ in a quartz cuvette. Size distribution was obtained by multiple data acquisitions (15) of $40 \mathrm{~s}$ each with a total of five replicates. The concentration of Casiopeína III-ia in the solutions used for the size determination of the aggregates was $10 \mathrm{mM}$. Data analysis was carried out using the Zetasizer v 7.11 software.

In order to determine the molecular weight of the Casiopeína III-ia aggregates, SLS measurements were performed with the same equipment as in the case of the DLS experiments described in detail above. For each concentration the data acquisition was collected from 10 measurements with a duration of $30 \mathrm{~s}$ each, with a total of five replicates. Data analysis was also carried out with the Zetasizer v 7.11 software supplied with the instrument.

\section{Results and discussion}

\section{Isothermal titration calorimetry}

Through isothermal titration calorimetry the energetics associated with the dissociation of Casiopeína III-ia aggregates in pure water and the phosphate $0.1 \mathrm{M}, \mathrm{pH}$ 7.4 media were determined. Figure 2 shows the resulting thermogram for both aqueous media where it is seen that the dissociation process is endothermic. As the concentration of Casiopeína III-ia progressively increases in the calorimetric cell during the course of the experiment, the 
resulting heat from the dissociation process decreases tending to a value of zero. As it is observed, the dissociation process of the Casiopeína III-ia aggregates follows the same trend in both aqueous media but the dissociation energy is remarkably different for each case. The amount of heat evolved after each addition of the solute in the phosphate $0.1 \mathrm{M}, \mathrm{pH} 7.4$ media is around 4 times higher in comparison to that obtained when titrating into pure water. In both cases the shape of the curve indicates that the number of monomers which participate in the formation of the aggregates is low, since aggregates with high number of monomers display normally a high cooperativity during the dissociation process and also the curve follows a sigmoidal trend which is centered near the critical aggregation concentration [11].

In order to obtain the thermodynamic parameters of the dissociation process the data was analyzed via an iterative nonlinear least square algorithm using a dissociation model where the fitting parameters are $K_{D}, \Delta H_{D}$ and the aggregation number [11, 12]. Figure 2 also shows the curves obtained using the values of the parameters from the best fit to the dissociation model, which show a good description of the theoretical model to the experimental data. The resulting values for $K_{D}, \Delta H_{D}$ and the aggregation number are $2.73 \times 10^{-4} \pm 0.3 \times 10^{-4} \mathrm{M}, 18.79 \pm 1.21 \mathrm{~kJ} \mathrm{~mol}^{-1}$ and 2.2 respectively for Casiopeína dissolved in pure water and $4.61 \times 10^{-4} \pm 0.6 \times 10^{-4} \mathrm{M}, 70.48 \pm 0.51 \mathrm{~kJ} \mathrm{~mol}^{-1}$ and 2.0 for Casiopeína dissolved in the buffer media.

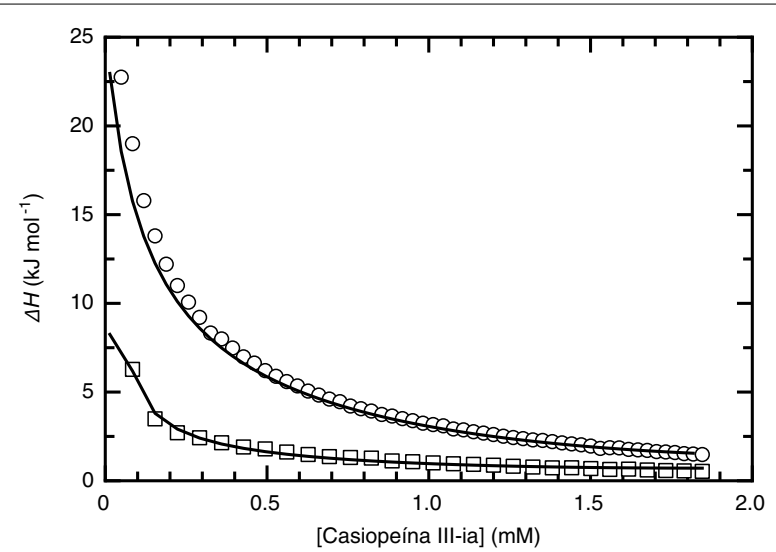

Fig. 2 Heat changes as a function of the total Casiopeína III-ia concentration in the calorimetric cell from ITC measurements carried out in two aqueous media. Circles correspond to the solute dissolved in the phosphate $0.1 \mathrm{M}$ and $\mathrm{pH} 7.4$ media and titrated into the same buffer while squares represent the solute dissolved in pure water and titrated into the same solvent. The lines correspond to the calculated heat changes using optimized values of $K_{D}, \Delta H_{D}$ and the stoichiometry of the aggregate formation equilibria $\left(x^{2}=0.0513\right.$ for Casiopeína dissolved in the phosphate media and $x^{2}=0.086$ for Casiopeína dissolved in pure water)
The number of monomers participating in the formation of the aggregates is very low as one would expect from the shape of the titration curve, as described previously. Data analysis shows that the aggregates are dimers which possess low dissociation constants in both aqueous media. The main difference between the two systems studied is the enthalpy of dissociation of the aggregates in the different aqueous media. The only fact responsible for such difference in enthalpy is the presence of the phosphate ions and therefore it must contribute energetically to the stabilization of the dimers, one could even speculate that the phosphates could participate directly in the aggregation process. This hypothesis is based in the fact that from our dynamic light scattering studies we have found that the hydrodynamic radii of the aggregates in the phosphate media are bigger in comparison to the ones present in pure water and is further elaborated in the article in another section (see discussion in "Dynamic light scattering and static light scattering analysis" section).

\section{Surface tension measurements}

For the two different aqueous media studied it was found that Casiopeína III-ia exhibits surface activity, since it is able to modify the surface tension as shown in the plots of surface tension as a function of concentration of the solute in Fig. 3. Its surface activity is not so strong as the one displayed by typical surfactant molecules which are able to decrease the value of surface tension by $30 \mathrm{mN}$ $\mathrm{m}^{-1}$ or more nevertheless, it is able to decrease the surface tension of pure water and the buffer solution media by 23 and $19 \mathrm{mN} \mathrm{m}^{-1}$ respectively. The concentration dependence of the surface tension for the two systems follows a different trend: (i) for pure water the surface tension decreases dramatically in the concentration range 0 to $1.5 \mathrm{mM}$ followed by a small region between 1.5 and $3 \mathrm{mM}$ where the surface tension remains constant, decreasing once more and remaining constant from around $4 \mathrm{mM}$ up to the final concentration and (ii) in the case of the buffer solution the surface tension decreases dramatically in the concentration range 0 to $3 \mathrm{mM}$, from where the surface tension remains constant (see Fig. 3).

The lack of a concentration dependence of the surface tension after a certain solute concentration is reached is associated with the ability of the solute to form aggregates in the bulk of the solution, for surfactants which are able to self-associate into micelles this concentration is called critical micelle concentration $(\mathrm{cmc})$. In the case that the aggregates are not micelles the term critical aggregation concentration $(c a c)$ is more appropriate. We have employed a Gibbs adsorption isotherm analysis in order to determine the cac value in each aqueous media. As shown in Fig. 3, Casiopeína III-ia has different 


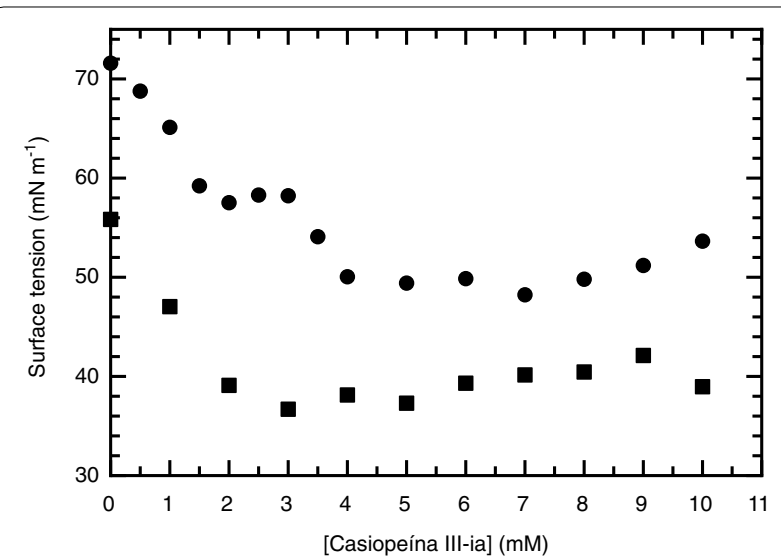

Fig. 3 Surface tension versus solute concentration for the two Casiopeína III-ia aqueous media reported in this work. Circles correspond to the solute dissolved in pure water while the squares represent the solute dissolved in the phosphate $0.1 \mathrm{M}, \mathrm{KNO}_{3} 0.1 \mathrm{M}$ and $\mathrm{pH} 7.4$ media

cac values for each of the aqueous media studied in this work. For pure water the cac value is $4.09 \mathrm{mM}$ while for the phosphate $0.1 \mathrm{M}, \mathrm{KNO}_{3} 0.1 \mathrm{M}$ and $\mathrm{pH} 7.4$ media it is $2.87 \mathrm{mM}$. As seen from the chemical structure of Casiopeína III-ia in Fig. 1, the compound has two organic ligands which are coordinated with the metallic center. From these two ligands 4, 4'-dimethyl-2, 2'-bipyridine has a low solubility in aqueous media which makes it the hydrophobic element of the coordination compound while the acetylacetonato moiety has a higher solubility, following these line of thought Casiopeína III-ia has the right chemical moieties to present surface activity. Regarding the differences in the cac values in each aqueous media the presence of the phosphate ions and the increment in the ionic strength promotes the aggregation process since the $c a c$ value is roughly half the value obtained in the pure water media. As it will be discussed in other sections of this article, the phosphate ions have a big influence in the physical characteristics of the Casiopeína III-ia aggregates.

\section{Conductivity measurements}

The concentration dependence profile of the electrical conductivity of the aqueous and the buffer Casiopeína III-ia solutions is shown in Fig. 4. In the case of the pure water solutions (Fig. 4, lower panel) the conductivity increases monotonically with the concentration of the solute which is the common trend observed for electrolyte solutions. Careful analysis of the full curve shows that there are two different linear trends which describe the observed data in the complete concentration range of our study. At low concentrations it is the concentration dependence of Casiopeína III-ia monomers which

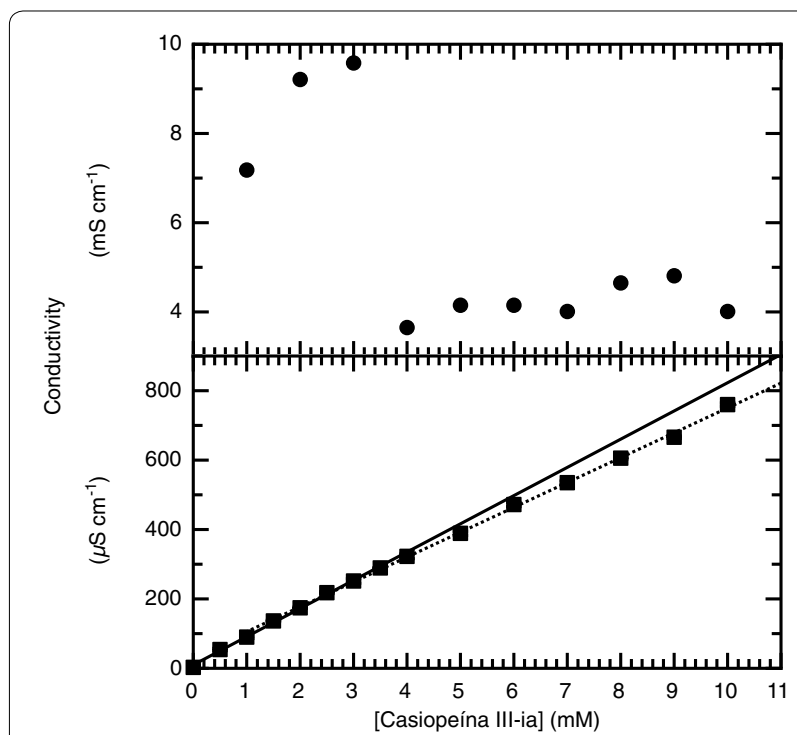

Fig. 4 Electrical conductivity dependence with concentration of the solute. The upper panel corresponds to Casiopeína III-ia dissolved in the phosphate $0.1 \mathrm{M}, \mathrm{KNO}_{3} 0.1 \mathrm{M}$ and $\mathrm{pH} 7.4$ media. The lower panel represents data collected for Casiopeína III-ia dissolved in pure water. Two linear concentration dependencies can be seen $\left(R^{2}=0.998\right.$ for the first region and $R^{2}=0.996$ for the second region), each corresponds to the different electrical conductivity concentration dependence that the free and the aggregate species possess

is seen. At a concentration range between 3 and $3.5 \mathrm{mM}$ a shift is observed in the linear electrical conductivity dependency with concentration. This behavior is associated with the formation of Casiopeína III-ia aggregates since no chemical reaction can occur in the conditions in which our study has been carried out. The difference in the electrical conductivity dependency between the monomers and the aggregates is due to the fact that the mobility and the charge of these species are not the same [10].

In the case of the phosphate $0.1 \mathrm{M}, \mathrm{KNO}_{3} 0.1 \mathrm{M}$ and $\mathrm{pH} 7.4$ media, the observed trend is dramatically different (Fig. 4, upper panel). The conductivity values are 1000 higher than those observed for Casiopeína III-ia dissolved in pure water which is the result of the presence of $\mathrm{KNO}_{3}$, which is a strong electrolyte, in the media. At low concentrations the normal monotonical increase of electrical conductivity with concentration is observed, but between the concentration range of 3 and $4 \mathrm{mM}$ the electrical conductivity falls sharply and then remains constant. The observed phenomenon is a mere result of the dramatic change in the charge and the mobility of the aggregates in comparison to the free Casiopeína III-ia molecules. The concentration range where the property changes significantly corresponds to the critical aggregation concentration. 
As it was mentioned in the "Conductivity measurements" section, the data analysis of the observed molar conductivity was done following the procedure described by Streng et al. [10]. The procedure described briefly is the following: data analysis is made considering that the monomer and the aggregate are strong electrolytes therefore the molar conductivity of both species can be expressed as linear functions of the square root of the concentration of each of the species, described by the following equation

$$
\begin{gathered}
\Lambda_{\mathrm{obs}}=\frac{\left(c_{T}-n c_{M}\right)}{c_{T}}\left(a-b \sqrt{c_{T}-n c_{M}}\right) \\
+\frac{c_{M}}{c_{T}}\left(a^{\prime}-b^{\prime} \sqrt{c_{M}}\right),
\end{gathered}
$$

where $c_{T}$ is the total concentration of the sample, $c_{M}$ is the concentration of the aggregate, $a$ is the limiting molar conductivity of the monomer i.e. the molar conductivity at infinite dilution, $b$ is the Kohlrausch constant for the monomer, $a^{\prime}$ is the limiting molar conductivity of the aggregate and $b^{\prime}$ is the Kohlrausch constant for the aggregate. The limiting molar conductivity of the monomer and the Kohlrausch constant of the monomer are obtained from a linear fit of the conductivity data in the low concentration range, below the critical aggregation concentration. The remaining parameters in Eq. 1 are obtained through a non-linear least squares regression fit of the observed molar conductivity data dependency with the square root of the concentration.

For both systems the observed molar conductivity, $\Lambda_{\text {obs }}$, as a function of the square root of the concentration is shown in Fig. 5. Strong electrolytes which do not form aggregates in aqueous media show a linear dependency. We found that Casiopeína III-ia is a potential electrolyte and the departure from linearity suggest that aggregation has occurred in the concentration range of study. Fitting the observed molar conductivity we have calculated the dissociation constant of the aggregates as well as the aggregation number. As seen from Fig. 5 there is a good agreement between the observed experimental data and the theoretical description. In Table 1 the parameters obtained from fitting the observed molar conductivity are summarized. The aggregation number, $n$, for both aqueous media obtained from this analysis are in good agreement with the ones we found from our dissociation studies using the ITC technique, indicating that the aggregates are formed with a low number of monomers. Also in good agreement with our ITC studies are the $K_{D}$ values obtained for both aqueous media.

\section{UV-Visible spectrophotometry}

For the aqueous and the phosphate $0.1 \mathrm{M}, \mathrm{KNO}_{3} 0.1 \mathrm{M}$ and $\mathrm{pH} 7.4$ media the UV-Visible absorbance spectrum

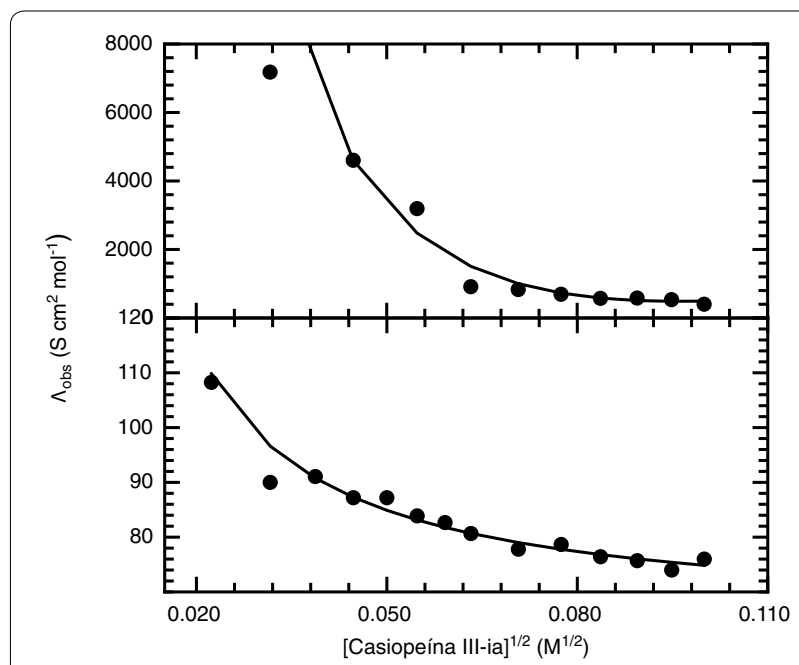

Fig. 5 Molar conductivity concentration dependence for Casiopeína III-ia dissolved in two different aqueous media. The upper panel corresponds to the solute dissolved in the phosphate $0.1 \mathrm{M}, \mathrm{KNO}_{3} 0.1 \mathrm{M}$ and $\mathrm{pH} 7.4$ media while the lower panel corresponds to the solute dissolved in pure water. The lines correspond to the best fit achieved with parameters summarized in Table 1

Table 1 Fitted values of the parameters of the molar conductivity dependency with concentration equation of Casiopeína III-ia in different aqueous media

\begin{tabular}{lll}
\hline Parameter & \multicolumn{2}{l}{ Aqueous media } \\
\cline { 2 - 3 } & Pure water & $\begin{array}{l}\text { Phosphate } \mathbf{0 . 1} \mathbf{~ M , ~} \mathbf{K N O}_{\mathbf{3}} \mathbf{~ O . 1} \mathbf{~ M} \text { and } \mathbf{~ p H} \\
\end{array}$ \\
\hline$n$ & 2 & 2 \\
$K_{D}$ & $5.93 \times 10^{-4} \mathrm{M}$ & $1.57 \times 10^{-3} \mathrm{M}$ \\
$a$ & 102.6 & 1020 \\
$b$ & 38.6 & 14,961 \\
$a^{\prime}$ & 0.0017 & 0.069 \\
$b^{\prime}$ & 0.109 & 0.870 \\
$x^{2}$ & 0.0016 & 0.0481 \\
\hline
\end{tabular}

$n$ aggregate number; $K_{D}$ dissociation constant; $a$ limiting molar conductivity of monomer; $b$ constant for monomer; $a^{\prime}$ limiting molar conductivity of aggregate; $b^{\prime}$ constant for the aggregate; $x^{2}$ is the value of the minimization function (Chi squared test) employed to find the best parameter set which describes the experimental data

was obtained in order to determine the best wavelength to follow the concentration dependency of the absorbance. For pure water it showed an absorption maxima centered at $598 \mathrm{~nm}$ while for the buffer media it is shifted to $627 \mathrm{~nm}$. The absorbance at these wavelengths was then followed for each system as a function of concentration. Typical monotonic absorbance dependency with concentration was observed but as in the case of electrical conductivity different lineal behaviors describe the whole concentration range as shown in Fig. 6. The observed 


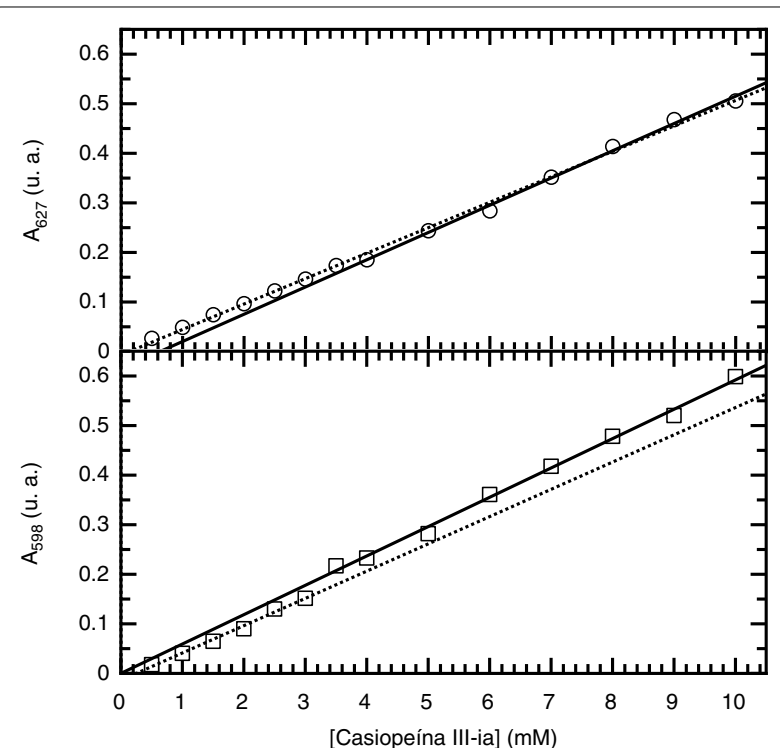

Fig. 6 UV-Vis absorbance dependence with concentration of the solute. The upper panel corresponds to Casiopeína III-ia dissolved in the phosphate $0.1 \mathrm{M}_{,} \mathrm{KNO}_{3} 0.1 \mathrm{M}$ and $\mathrm{pH} 7.4$ media while the lower panel represents data collected for Casiopeína III-ia dissolved in pure water. Both systems follow an increment of absorbance with solute concentration but two linear dependencies are required for the full solute concentration range $\left(R^{2}=0.999\right.$ for the lower concentration range and $R^{2}=0.998$ for the upper concentration range of Casiopeína dissolved in phosphate media. $R^{2}=0.996$ for the lower concentration range and $R^{2}=0.998$ for the upper concentration range of Casiopeína dissolved in pure water)

shift in absorbance must be due to effects on the effective dielectric constant of the aggregates which modify the excited states of the molecules and not to the presence of turbidity, which was not observed. In fact, the samples were kept at room temperature for a month and there was no indication of precipitation. The concentration where there is a shift in the absorbance dependency with concentration is then considered as the critical aggregation concentration. For the pure aqueous media this corresponds to a concentration range between 3 and $3.5 \mathrm{mM}$ and 3.5 and $4 \mathrm{mM}$ for the phosphate $0.1 \mathrm{M}, \mathrm{KNO}_{3} 0.1 \mathrm{M}$ and $\mathrm{pH} 7.4$ media.

\section{Dynamic light scattering and static light scattering analysis} Our dynamic light scattering studies reveal that Casiopeína III-ia forms aggregates and the size of the observed aggregates is different in each of the aqueous media studied in this work. The DLS studies were performed in systems where Casiopeína III-ia is dissolved in: (i) pure water, (ii) phosphate $0.1 \mathrm{M}$, and $\mathrm{pH} 7.4$ and (iii) phosphate $0.1 \mathrm{M}, \mathrm{KNO}_{3} 0.1 \mathrm{M}$ and $\mathrm{pH} 7.4$ media. For the different aqueous media studied it is found that the populations of the aggregates are not homogeneous,

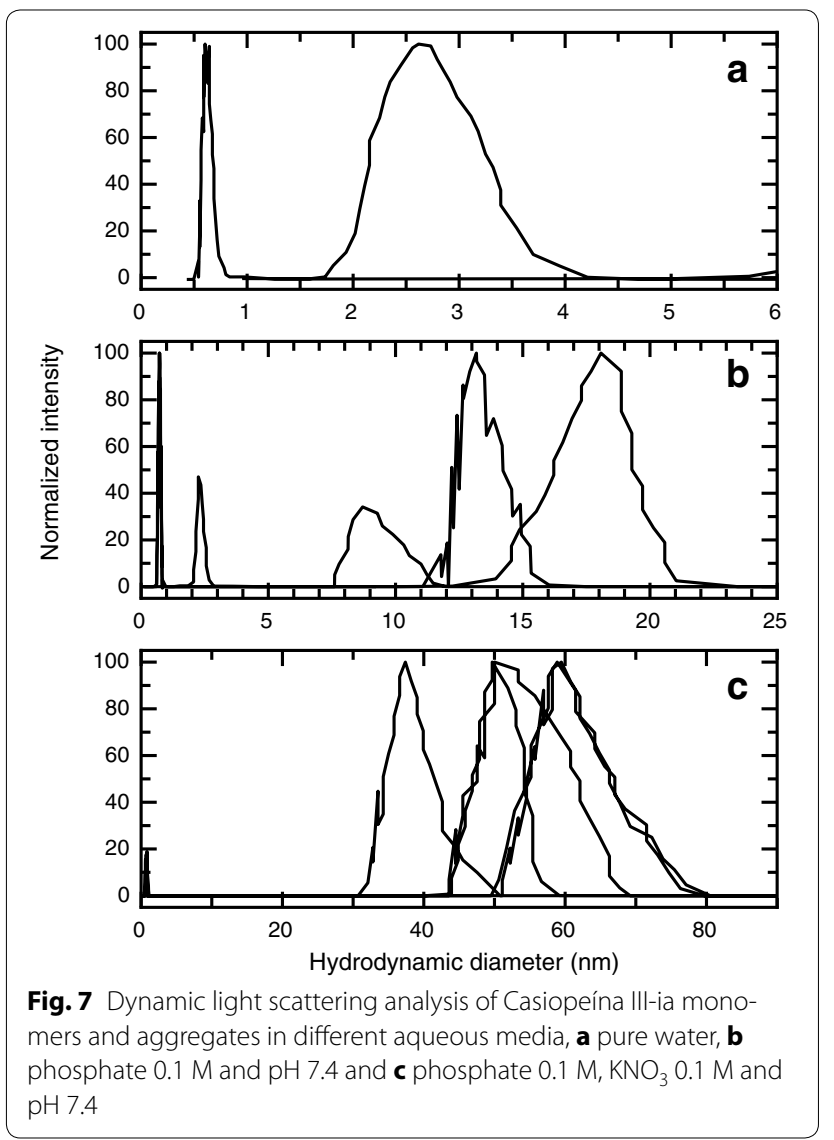

but within the polydispersity of the media there are well differentiated populations which we have assigned in the following way (Fig. 7): (i) for all the aqueous media there is a population with a mean hydrodynamic diameter around $0.66-0.95 \mathrm{~nm}$ which corresponds to the monomers i.e. singly dispersed Casiopeína III-ia molecules. This value corresponds well to the molecular diameter of $0.808 \mathrm{~nm}$ estimated from van der Waals radii calculated with the help of the software Marvin v. 15.8.31, 2015 which was used together with its calculator plugins (ChemAxon, http://www.chemaxon.com) and the molecular diameter of $0.82 \mathrm{~nm}$ reported in the literature and obtained from an X-Ray diffraction characterization [13], (ii) there are small aggregates present in the systems where Casiopeína III-ia is dissolved in pure water and in the phosphate $0.1 \mathrm{M}$ and $\mathrm{pH} 7.4$ media, and which have a hydrodynamic diameter centered around $2.70 \mathrm{~nm}$. For the phosphate $0.1 \mathrm{M}, \mathrm{KNO}_{3} 0.1 \mathrm{M}$ and $\mathrm{pH}$ 7.4 media interestingly this population is not present and would indicate that the ionic strength of the media plays and important role in the aggregate size and (iii) there are bigger aggregates with hydrodynamic diameters centered around 9.15, 13.17, 18.45, 39.89, 58.87 and $67.03 \mathrm{~nm}$ which are present only in the systems where Casiopeína 
III-ia is dissolved in the buffered aqueous media. Interestingly the bigger aggregates are present when $\mathrm{KNO}_{3}$ $0.1 \mathrm{M}$ is added in the media. These facts clearly indicate that the ionic strength of the media has a strong influence over the solvation sphere around the Casiopeína III-ia aggregates.

For the buffered media these observations seem to be in contradiction to the results and analysis we obtained in calorimetry and conductometry regarding the size of the aggregates since the DLS results indicate that the aggregate size increases with ionic strength and therefore one would expect a higher aggregation number for these systems, while the other results indicate that the aggregates have a low aggregation number. Our hypothesis in order to reconcile these conflicting observations is the following: Through our calorimetry and conductometry analysis we have determined the number of Casiopeína III-ia molecules which participate in the formation of an aggregate, and this number is around two. In the presence of phosphate and $\mathrm{KNO}_{3}$ our DLS results indicate that the Casiopeína III-ia dimer is surrounded by phosphate ions which increase the hydration layer around the aggregate due to the fact that they are much bulkier than the water molecules. Either a coordination between the metallic center of the Casiopeína III-ia and the phosphate and/or through electrostatic interactions this hydration layer is bigger in comparison to the one formed when the solute is dissolved in pure water. It is known that the copper (II) ion dissolved in phosphate buffer at a $\mathrm{pH}$ of 7.4 is not in the form of the aquacation or hydrolytic species but as the $\left[\mathrm{Cu}\left(\mathrm{HPO}_{4}\right)\right]$ specie [14]. In the Casiopeína III-ia coordination compound the copper (II) ion is able to coordinate with the phosphate species $\left(\mathrm{HPO}_{4}{ }^{2-}\right.$ or $\left.\mathrm{H}_{2} \mathrm{PO}_{4}{ }^{-}\right)$ replacing the water molecule and therefore it is able to form hydrogen phosphate bridges with other Casiopeína III-ia aggregates. These hydrogen phosphate bridges have been reported for coordination compounds with copper (II) as the metallic center [15-17], and also with other coordination compounds where the metallic centers are vanadium and zirconium $[18,19]$. These hydrogen phosphate bridges could also explain the reason why in our calorimetric studies we found a higher value of $\Delta H_{D}$ for the dissociation of the Casiopeína III-ia aggregates in the buffer media in comparison with the pure water media.

Adding an electrolyte $\left(\mathrm{KNO}_{3}\right)$ to the phosphate media promotes the growth of the solvation layer due to a shielding effect. It would seem that more layers of phosphate are able to build up around the Casiopeína III-ia dimer or/and that neighboring aggregates with their solvation sphere are able to group through electrostatic interactions or hydrogen bonding. It is reported in the literature that some copper (II) coordination compounds are able to form double anti parallel polymer chains which are kept together by strong phosphate-water bonds [14, 20]. Although from our findings it is clear that Casiopeína III-ia does not form such polymers it is undoubted that the phosphate media is responsible for the increase in size of the observed aggregates. The fact that the properties of the aggregate are different or are altered by the addition of ions has been well reported in the literature $[21,22]$.

From the SLS measurements it is possible to determine the molecular weight of the aggregates in solution. Polydispersity of a sample produces bad estimates for the determination of the molecular weight. Since we found a much lower polydispersity in the case where Casiopeína III-ia is dissolved in water we centered our efforts into characterizing the molecular weight of the resulting aggregates only for this system. The molecular weight of the aggregates is estimated by measuring the scattered light of different concentrations of the sample and applying Rayleigh's equation, which describes the intensity of the scattered light from a particle in solution [23].

$$
\frac{K C}{R_{\Theta}}=\left(\frac{1}{M}\right)+2 A_{2} C
$$

where $K$ is the optical constant, $C$ is the concentration of the sample, $M$ is the sample molecular weight, $R_{\Theta}$ is the Rayleigh ratio i.e. the ratio of the scattered light to incident light of the sample and $A_{2}$ is the second virial coefficient. Since we are interested in finding the molecular weight of the aggregates the concentration range of our studies involves concentrations higher than the critical aggregation concentration (from 5 to $10 \mathrm{mM}$ ). The results obtained from our SLS studies are depicted in Fig. 8 and as it is seen, the intensity of the scattered light from the samples is proportional to the concentration of the Casiopeína III-ia. From Rayleigh's equation the molecular weight of the Casiopeína aggregates can be calculated from the intercept at zero concentration. The resulting molecular weight of the aggregates was determined to be $1000.015 \pm 51 \mathrm{~g} \mathrm{~mol}^{-1}$, and given that the molecular weight of the Casiopeína III-ia molecule is $444.92 \mathrm{~g} \mathrm{~mol}^{-1}$ it results then that the number of monomers participating in the aggregate formation is 2.24. This numerical value is in agreement with our other determinations of the number of aggregation employing isothermal titration calorimetry and data analysis of the molar conductivity dependency with concentration of the solute.

Since Casiopeína III-ia is a member of around 100 compounds in the family of the Casiopeínas our results indicate that several members of this family could be capable of forming aggregates at a certain concentration due to the nature of the ligands employed to synthesize these copper coordination compounds. The need to 


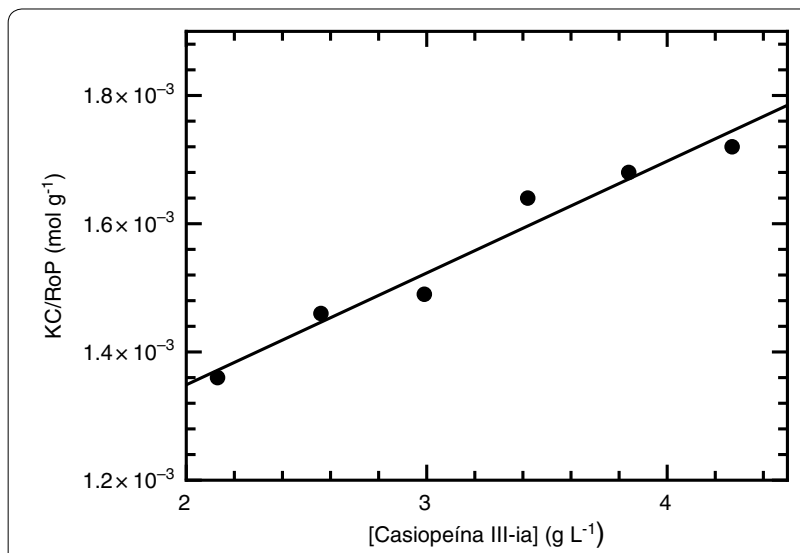

Fig. 8 Debye plot of Casiopeína III-ia dissolved in pure water. Circles represent the experimental data from the Static Light Scattering measurements while the line corresponds to the fitted curve obtained from fitting the experimental data to Rayleigh's equation $\left(R^{2}=0.978\right)$

carry out physicochemical studies in order to determine the aggregation properties of this compounds is of great importance since other compounds of the family of the Casiopeínas have also shown antitumor and anti-protozoan activity [7, 24-26].

\section{Conclusions}

Based in the data collected from the different experimental techniques employed in this study it is concluded that Casiopeína III-ia is able to self-associate in aqueous media at $25^{\circ} \mathrm{C}$. The physicochemical parameters associated with the formation of these aggregates: critical aggregation concentration, aggregation number, dissociation constant and the enthalpy of dissociation were determined. There is a very good agreement for the values of $K_{D}$ and the aggregation number obtained from data analysis carried out from our electrical conductivity measurements and isothermal titration calorimetry. From our studies we determined that for pure water the number of monomers participating in the aggregates is low (around two). This result is in agreement with reported aggregation numbers of several non-peptide surface active drugs in water, whose aggregation numbers vary from 3 to $12[27,28]$.

The presence of the phosphate and electrolytes does not change the number of Casiopeína III-ia molecules which aggregate but they have an important effect in energetic terms and in the formation of a bigger hydration shell around the aggregates. With the information we have collected and analyzed from our studies using different experimental techniques we are not able to establish how the monomers are interacting to form the aggregates but due to the electrolyte nature of Casiopeína III-ia one can assume that the likely interactions should include cation-cation dimer, hydrogen bonding or $\pi-\pi$ interactions. In fact, it is known from X-ray diffraction that many members of the Casiopeína family form in the solid state stacked structures stabilized through $\pi-\pi$ interactions between the bipyridine or the phenanthroline moieties of the molecule [29, 30].

\section{Abbreviations \\ Casiopeína III-ia: [Cu(4, 4'-dimethyl-2, 2'-bipyridine)(acetylacetonato) $\left.\mathrm{H}_{2} \mathrm{O}\right]$ $\mathrm{NO}_{3}$; SLS: static light scattering; DLS: dynamic light scattering; cac: critical aggregation concentration; ITC: isothermal titration calorimetry; $K_{D}$ : dissocia- tion constant; $H_{D}$ : enthalpy of dissociation; $\Lambda_{\mathrm{obs}}$ : observed molar conductivity; a: limiting molar conductivity of the monomer; b: Kohlrausch constant for the monomer; $\mathrm{a}^{\prime}$ : limiting molar conductivity of the aggregate; $\mathrm{b}^{\prime}$ : Kohlrausch constant for the aggregate.}

\section{Authors' contributions}

AMM carried out the UV-Vis, conductivity, DLS and SLS measurements. ECN carried out the ITC, surface tension, DLS and SLS measurements. JCGR carried out the synthesis and characterization of the coordination compound and participated in data analysis. LRA participated in data analysis. All authors read and approved the final manuscript.

\section{Author details}

${ }^{1}$ Laboratorio de Biofisicoquímica, Departamento de Fisicoquímica, Facultad de Química, Universidad Nacional Autónoma de México, Mexico, D. F. 04510, Mexico. ${ }^{2}$ Departamento de Química Inorgánica y Nuclear, Facultad de Química, Universidad Nacional Autónoma de México, Mexico, D. F. 04510, Mexico. ${ }^{3}$ Departamento de Fisicoquímica, Instituto de Química, Universidad Nacional Autónoma de México, Mexico, D. F. 04510, Mexico.

\section{Acknowledgements}

E C-N acknowledges the financial support provided by the Faculty of Chemistry (PAIP 5000-9024) and Dirección General de Asuntos del Personal Académico (Proyecto PAPIIT IA207116) both from U. N. A. M. L R-A thanks CONACYT (Grant Number 179119) for funding part of this work. We thank Dr. Ismael Bustos from the Faculty of Medicine at U. N. A. M. for allowing us to use his DLS instrument in order to carry out our DLS and SLS experiments.

\section{Competing interests}

The authors declare that they have no competing interests.

Received: 28 April 2016 Accepted: 15 October 2016

Published online: 21 October 2016

\section{References}

1. Azuara LR (1992) Process to obtain new mixed copper aminoacidate complexes from phenylate phenanthroline to be used as anticancerigenic agents. US Patent No. 5, 107, 005

2. Azuara LR (1996) Process to obtain new mixed copper aminoacidate complexes from methylatephenanthroline to be used as anticancerigenic agents. US Patent No. 5, 576, 326

3. Gutiérrez AG, Vázquez-Aguirre A, García-Ramos JC, Flores-Alamo M, Hernández-Lemus E, Ruiz-Azuara L, Mejía C (2013) Copper(II) mixed chelate compounds induce apoptosis through reactive oxygen species in neuroblastoma cell line CHP-212. J Inorg Biochem 125:17-25

4. Serment-Guerrero J, Cano-Sanchez P, Reyes-Perez E, Velázquez-García F, Bravo-Gomez ME, Ruiz-Azuara L (2011) Genotoxicity of the copper antineoplastic coordination complexes casiopeinas. Toxicol In Vitro 25:1376-1384

5. Carvallo-Chaigneau F, Trejo-Solis C, Gómez-Ruiz C, Rodríguez-Aguilera E, Macías-Rosales L, Cortés-Barbarena E, Cedillo-Peláez C, Gracia-Mora I, Ruíz-Azuara L, Madrid-Marina V, Constantino-Casas F (2008) Casiopeina III-ia induces apoptosis in HCT-15 cells in vitro through caspase-dependent mechanisms and has antitumor effect in vivo. Biometals 21:17-28 
6. Rivero-Müller A, De Vizcaya-Ruiz A, Plant N, Ruíz-Azuara L, Dobrota M (2007) Mixed chelate copper complex, Casiopeina Ilgly, binds and degrades nucleic acids: a mechanism of cytotoxicity. Chem Biol Interact 165:189-199

7. Valencia-Cruz Al, Uribe-Figueroa LI, Galindo-Murillo R, Baca-López K, Gutiérrez AG, Vázquez-Aguirre A, Ruiz-Azuara L, Hernández-Lemus E, Mejía C (2013) Whole genome gene expression analysis reveals Casiopeína-induced apoptosis pathways. Plos ONE 8:e54664

8. Schreier S, Malheiros SVP, de Paula E (2000) Surface active drugs: self-association and interaction with membranes and surfactants. Physicochemical and biological aspects. Biochim Biophys Acta 1508:210-234

9. Schreiber G, Keating AE (2011) Protein binding specificity versus promiscuity. Curr Opin Struct Biol 21:50-61

10. Streng WH, Yu DH-S, Zhu C (1996) Determination of solution aggregation using solubility, conductivity, calorimetry, and $\mathrm{pH}$ measurements. Int Pharm 135:43-52

11. Velázquez-Campoy A, Ohtaka H, Nezami A, Muzammil S, Freire E (2004) Isothermal titration calorimetry. Curr Protoc Cell Biol 17:81-824

12. Luke K, Apiyo D, Wittung-Stafshede P (2005) Dissecting homo-heptamer thermodynamics by isothermal titration calorimetry: entropy driven assembly of co-chaperonin protein 10. Biophys J 89:3332-3336

13. Tovar-Tovar A, Ruíz-Ramírez L, Campero A, Romerosa A, Moreno-Esparza R, Rosales-Hoz MJ (2004) Structural and reactivity studies on 4, 4'-dimethyl-2, 2'-bipyridine acetylacetonato copper (II) nitrate (CASIOPEINA III$\mathrm{ia}^{\circledR}$ ) with methionine by UV-visible and EPR techniques.J Inorg Biochem 98:1045-1053

14. Bonomo RP, Impellizzeri G, La Mendola D, Maccarrone G, Pappalardo G, Santoro A, Tabbi G, Vecchio G, Rizzarelli E (2003) Functional mimics of Cu, Zn- superoxide dismutase enzymes. In: Russo N, Salahub DR, Witko M (eds) Metal-ligand interactions. Springer, Netherlands, pp 41-63

15. Youngme S, Phuengphai P, Chaichit N, Pakawatchai C, van Albada GA Roubeau O, Reedijk J (2004) The coordination chemistry of mono(di2-pyridylamine) copper(II) complexes with monovalent and divalent oxoanions: crystal structure, spectroscopic and magnetic properties of dinuclear $\left[\mathrm{Cu}(\mathrm{L})\left(\mu-\mathrm{H}_{2} \mathrm{PO}_{4}\right)\left(\mathrm{H}_{2} \mathrm{PO}_{4}\right)\right]_{2}$ and polynuclear $\left[\mathrm{Cu}(\mathrm{L})\left(\mu_{3}-\mathrm{HPO}_{4}\right)\right]_{\text {n. }}$. Inorg Chim Acta 357:3603-3612

16. Phuengphai S, Youngme S, Pakawatchai C, vanAlbada GA, Quesada M, Reedijk J (2006) Synthesis, crystal structure and magnetic properties of an unexpected new coordination $\mathrm{Cu}(\mathrm{II})$ compound, containing two different phosphato-bridged dinuclear units; $\left[\mathrm{Cu}_{2}(\text { phen })_{2}(\mu-\right.$ $\left.\left.\mathrm{H}_{2} \mathrm{PO}_{4}-\mathrm{O}, \mathrm{O}^{\prime}\right)_{2}\left(\mathrm{H}_{2} \mathrm{PO}_{4}\right)_{2}\right]\left[\mathrm{Cu}_{2}(\text { phen })_{2}\left(\mu-\mathrm{H}_{2} \mathrm{PO}_{4}-\mathrm{O}, \mathrm{O}^{\prime}\right)\left(\mu-\mathrm{H}_{2} \mathrm{PO}_{4}-\mathrm{O}\right)(\mu\right.$ $\left.\left.-\mathrm{HPO}_{4}-\mathrm{O}\right)\right]_{2}\left(\mathrm{H}_{2} \mathrm{O}\right)_{9}($ phen $=1,10$-phenanthroline). Inorg Chem Commun 9:147-151

17. Phuengphai P, Youngme S, Chaichit N, Pakawatchai C, van Albada GA, Quesada M, Reedijk J (2006) Crystal structures and magnetic properties of two new phosphate-metal complexes: $\left[\mathrm{Cu}_{2}(\mathrm{bpy})_{2}\left(\mu, \eta^{2}-\mathrm{HPO}_{4}\right)-(\mu\right.$, $\left.\left.\eta^{1}-\mathrm{H}_{2} \mathrm{PO}_{4}\right)\left(\mu, \eta^{2}-\mathrm{H}_{2} \mathrm{PO}_{4}\right)\right] \mathrm{n}$ and $\left[\mathrm{Cu}_{4}(\text { phen })_{4}\left(\mu_{3}, \eta^{2}-\mathrm{HPO}_{4}\right)_{2}-\left(\mu, \eta^{2}-\right.\right.$ $\left.\left.\mathrm{H}_{2} \mathrm{PO}_{4}\right)_{2}\left(\mathrm{H}_{2} \mathrm{PO}_{4}\right)_{2}\right]\left(\mathrm{H}_{2} \mathrm{O}\right)_{4}$. Polyhedron 25:2198-2206
18. Zhang Y, Haushalter RC, Zubieta J (1997) Hydrothermal synthesis and crystal and molecular structure of a binuclear dioxovanadium $(V)$ species exhibiting a bridging $\mathrm{HPO}^{2-}$ ligand, $\left[\left(\mathrm{VO}_{2}\right)_{2}\left(\mathrm{HPO}_{4}\right)\left(2,2^{\prime} \text {-bipy }\right)_{2}\right] \cdot \mathrm{H}_{2} \mathrm{O}$. Inorg Chim Acta 260:105-110

19. Krogh-Andersen AM, Norby P, Hanson JC, Vogt T (1998) Preparation and characterization of a new 3-dimensional zirconium hydrogen phosphate, $\mathrm{T}-\mathrm{Zr}\left(\mathrm{HPO}_{4}\right)_{2}$. Determination of the complete crystal structure combining synchrotron X-ray single-crystal diffraction and neutron powder diffraction. Inorg Chem 37:876-881

20. Xu L, Wang E, Peng J, Huang RA (2003) Novel coordination polymer with double chains structure: hydrothermal syntheses, structures and magnetic properties of $\left[\mathrm{Cu}(\mathrm{phen})\left(\mathrm{H}_{2} \mathrm{O}\right)_{2} \mathrm{SO}_{4}\right]_{n}$ (phen = 1,10-phenanthroline). Inorg Chem Commun 6:740-743

21. Mukerjee P, Mysels K, Kapauan P (1967) Counterion specificity in the formation of ionic micelles-size, hydration, and hydrophobic bonding effects. J Phys Chem 71:4166-4175

22. Lukanor B, Firoozabadi A (2014) Specific ion effects on the self-assembly of ionic surfactants: a molecular thermodynamic theory of micellization with dispersion forces. Langmuir 30:6373-6383

23. Some D (2013) Light-scattering-based analysis of biomolecular interactions. Biophys Rev 5:147-158

24. Mejía C, Ruíz-Azuara L (2008) Casiopeínas Ilgly and Illia induce apoptosis in Medulloblastoma cells. Pathol Oncol Res 14:467-472

25. López-Rodríguez A, Cárabez-Trejo A, Rosas-Sánchez F, Mejía C, RuízAzuara L, Miledi R, Martínez-Torres A (2011) The metal coordinated Casiopeína IIIEa induces the petite-like phenotype in Saccharomyces cerevisiae. Biometals 24:1189-1196

26. Becco L, Rodríguez A, Bravo ME, Prieto MJ, Ruiz-Azuara L, Garat B, Moreno V, Gambino D (2012) New achievements on biological aspects of copper complexes Casiopeína ${ }^{\circledR}$ : Interaction with DNA and proteins and antiTrypanosoma cruzi activity. J Inorg Biochem 109:49-56

27. Causon D, Gettings J, Gormally J, Greenwood R, Natarajan N, Wyn-Jones E (1981) Ultrasonic relaxations associated with aggregation in drugs. J Chem Soc Faraday Trans 77:143-151

28. Taboada P, Pérez-Rodríguez M, Attwood D, Varela LM, Ruso JM, Mosquera $\checkmark$ (2001) Self-association of Verapamil in aqueous electrolyte solution. J Colloid Interface Sci 241:459-464

29. Alvarez-Larena A, Briansó-Penalva JL, Piniella JF, Moreno-Esparza R, RuizRamírez L, Ferrer-Sueta G (1995) Aqua(glycinato)(3, 4, 7, 8-tetramethyl-1, 10-phenanthroline)copper(II) Nitrate. Acta Crystallogr Sect C 51:852-854

30. García-Ramos JC, Galindo-Murillo R, Tovar-Tovar A, Alonso-Saenz AL, Gómez-Vidales V, Flores-Alamo M, Ortiz-Frade L, Cortes-Guzmán F, Moreno-Esparza R, Campero A, Ruíz-Azuara L (2014) The $\pi$-back-bonding modulation and its impact in the electronic properties of $\mathrm{Cu}(\mathrm{II})$ antineoplastic compounds: an experimental and theoretical study. Chem Eur J 20:13730-13741

\section{Submit your manuscript to a SpringerOpen ${ }^{\circ}$ journal and benefit from:}

- Convenient online submission

- Rigorous peer review

- Immediate publication on acceptance

- Open access: articles freely available online

- High visibility within the field

- Retaining the copyright to your article

Submit your next manuscript at $\boldsymbol{\nabla}$ springeropen.com 